\title{
General Psychiatry Non-suicidal self-injury in Shanghai inner bound middle school students
}

To cite: Zhang F, Cloutier PF, Yang $\mathrm{H}$, et al. Non-suicidal self-injury in Shanghai inner bound middle school students. General Psychiatry 2019;32:e100083. doi:10.1136/ gpsych-2019-100083

- Additional material is published online only. To view please visit the journal online (http://dx.doi.org/10.1136/ gpsych-2019-100083).

Received 09 May 2019 Revised 28 June 2019 Accepted 19 July 2019

Check for updates

(C) Author(s) (or their employer(s)) 2019. Re-use permitted under CC BY-NC. No commercial re-use. See rights and permissions. Published by BMJ.

${ }^{1}$ Department of Medical psychology, Shanghai General hospital, Medical School of Shang Hai Jiaotong University, Shanghai, China

${ }^{2}$ Children's Hospital of Eastern

Ontario, Ottawa, Ontario, Canada

${ }^{3}$ Shanghai Jing'an Education

College, Shanghai, China

${ }^{4}$ Shanghai Mental Health Center,Medical School of

Shang Hai Jiaotong University,

Shanghai, China

Correspondence to Wenhong Cheng; chengwhb@aliyun.com

Professor Zeping Xiao; xiaozeping88@163.com

\author{
Fang Zhang, ${ }_{4}^{1}$ Paula F Cloutier, ${ }^{2}$ Hongmei Yang, ${ }^{3}$ Wenjing Liu, ${ }^{4}$ Wenhong Cheng, ${ }^{1,4}$ \\ Zeping Xiao ${ }^{4}$
}

\begin{abstract}
Background Non-suicidal self-injury (NSSI) behaviour is very common among adolescents. Its prevalence and behavioural characteristics may vary according to regional and cultural differences. Investigation of NSSI locations and diagnosis of adolescents with NSSI are relatively lacking in China.

Aims The study objective was to determine the prevalence and features of NSSI among middle school students in Shanghai.

Methods The participants were from grade 6 to 8 selected from three junior schools in Jing'an District. Consenting students completed the Ottawa Self-Injury Inventory to determine the prevalence and characteristics of NSSI. Those who indicated NSSI within the past month were administered the Mini-International Neuropsychiatric Interview for Children and Adolescents to assess for emotional disorders.
\end{abstract}

Result The result shows 510 participants (21.7\%; mean age 13.51 (0.97) years old; $56.7 \%$ female) reported at least one instance of NSSI during the previous 12 months. NSSI was significantly more common in girls than boys ( $24.9 \%$ vs $\left.18.5 \% ; \chi^{2}=14.03, p=0.00\right)$. Commonly reported reasons for NSSI were for internal and external emotion regulation $(87.9 \%, 82.3 \%)$ and social influence $(57.8 \%)$. Anxiety disorders were the most common (28.9\%) disorder associated with NSSI.

Conclusion The rate of NSSI of middle school students in Shanghai inner bound is similar to those reported in North American and European youth. It is essential that school mental health professionals are aware of how to manage NSSI within the school setting.

\section{INTRODUCTION}

Non-suicidal self-injury (NSSI) is defined as the deliberate destruction of body tissue without suicidal intent. ${ }^{12}$ NSSI often starts in adolescence ${ }^{1-3}$ and those with an earlier age of onset report greater frequency and methods of NSSI, NSSI-related hospital visits, and are more likely to have a suicide plan. ${ }^{4}$ The international lifetime prevalence rate of NSSI in adolescents is $17 \%(8.0-26.3),{ }^{5}$ but most studies on rates and characteristics of adolescent NSSI are North American and European. Limited research mainly conducted in Hong Kong, and Taiwan and Guangdong reported a 12-month prevalence rate of NSSI in Chinese adolescents ranging from $17.0 \%$ to $33.6 \% .^{6-8}$ We are unaware of any prevalence studies in Chinese middle school students from Shanghai.

Martin and colleagues ${ }^{1}$ reported that self-injury in females peaked between 15 and 24 years of age and for males between 10 and 19 years of age. Gratz and colleagues ${ }^{9}$ extended research on the characteristics associated with NSSI by examining the ways in which gender, racial/ethnic background and school level interact. Their research found that the rates of NSSI varied as a function of gender, racial/ ethnic background and school level, as well as their interactions with African-American boys reporting higher rates of NSSI behaviours than their peers with the difference more obvious in middle school.

In addition to rates of NSSI, researchers have also examined other characteristics of NSSI behaviour, such as type and location of self-injury. Numerous types of NSSI have been reported in studies including cutting, headbanging, hitting and biting. ${ }^{2}{ }^{10}$ Beyond prevalence rates and methods, research on the body location of NSSI remains limited. A small number of studies have shown that the common injury locations involve the arms, legs and the head, with gender differences reported for type and location of injury among adolescents. ${ }^{310}$ For example, Hanania and colleagues ${ }^{3}$ investigated the characteristics of NSSI in a sample of 952 Jordanian adolescents ( $49.8 \%$ female) between the ages of 11 and 19 years and found that females were more likely than males to engage in cutting. Conversely, males were more likely than females to report self-punching; females were more likely to injure their arms and legs, whereas males were more likely to injure their jaw, face and genitals.

Surveying NSSI behaviour among middle school students in Shanghai can supplement the existing research on adolescents in China. Investigating self-injury in Shanghai students helps to further understand the characteristics of this behaviour in Chinese 
adolescents, and also extends the research on this behaviour beyond North American and European countries. In addition to the attention paid to the prevalence of NSSI behaviour, the methods and location of self-injury, the function and motivation of self-injury are also very important issues.

According to existing research, emotion regulation is the most common motivation for NSSI, ${ }^{1}$ followed by relationship influence and social control. ${ }^{10}$ Most research on the functions of NSSI was conducted on North American samples with few studies investigating Chinese adolescents. One exception is a study by You and colleagues ${ }^{11}$ who investigated the functions of NSSI in high school students in Hong Kong. They found that within the social influence function, 'to feel more a part of a group' received the highest mean endorsement, contradicting to the previous studies in western adolescent samples which found that this function was among the least endorsed. ${ }^{12}{ }^{13}$ The function 'to punish self' had a low score in You et al's study but was the second most important function after emotional regulation in many western samples. ${ }^{14}$ This led the authors to speculate that this inconsistency may be due to a cultural difference in attitude towards relationships and autonomy, such that western countries emphasise individualism while China emphasises collectivism. ${ }^{15}$ There is insufficient research evidence on the functions of NSSI in youth from mainland China.

Although it is well known that NSSI occurs in many patients with mental illness, there are few studies with middle school samples on the identification and evaluation of NSSI in youth using standard diagnostic tools. Understanding the function and mental health of students who engage in NSSI is necessary for prevention and early intervention efforts. The objective of this exploratory study was to determine the prevalence and features of NSSI among middle school students in Shanghai.

\section{METHODS}

\section{Sample}

The participants were from a previous research study: the assessment study on the mental health needs of children and adolescents aged 4-18 years in Shanghai. ${ }^{16}$ From the seven districts selected at that time, one district was randomly chosen, namely Jing'an District, and then three public schools were randomly selected from within. The sample was 2402 adolescents aged 12-16 years (female $(\mathrm{n}=1158,49.3 \%)$; male $(\mathrm{n}=1193,50.7 \%))$. The sample was drawn from 68 classes and included students from grade $6(n=783)$, grade $7(n=800)$ and grade $8(n=819)$.

Inclusion criteria: Junior high school students at school presently. Parents and children agreed to participate in the survey.

Exclusion criteria: Those who were unable to understand or complete questionnaires due to severe brain and body diseases and mental disorders.
Measures

Ottawa Self-Injury Inventory

The Ottawa Self-Injury Inventory $(\mathrm{OSI})^{17}$ is a self-report questionnaire assessing NSSI in great detail including 1-month, 6-month and 12-month prevalences of occasional and repetitive NSSI as well as the context of NSSI, its functions, alternative coping strategies and potential addictive features. The prevalence of NSSI was determined by asking how often acts of NSSI were present within the time frame ('how often in the past month/ in the past 6 months have you actually injured yourself without the intention to kill yourself?'). This questionnaire has been used in inpatients, outpatients ${ }^{18} 19$ and community samples. ${ }^{20}$ In order to use the OSI with Chinese adolescents, minor changes were necessary. Preliminary findings indicate that the reliability and validity of the Chinese version are satisfactory. ${ }^{21}$

The Mini-International Neuropsychiatric Interview for Children and Adolescents (MINI-KID) was used. ${ }^{22}$ Its widely used structured clinical diagnostic interview was designed to assess the presence of the Diagnostic and Statistical Manual of Mental Disorders Fourth Edition and the International Classification of Diseases Tenth Revision psychiatric disorders in children and adolescents aged 6-17 years in a way that is comprehensive and concise. Research has shown that the MINI-KID generates reliable and valid psychiatric diagnoses. ${ }^{22}$ In 2011, Yuxin Liu and Wang ${ }^{23}$ translated the tool into Chinese and the authors reported good test-retest reliability $(r=0.90)$ and a high consistency between raters with kappa above 0.80 .

\section{Procedure}

The study proceeded in two phases, that the first was an in-class group administration of the frequency of NSSI, and the second was a group administration of the OSI for students who reported NSSI and an individual administration of the MINI-KID for students who reported NSSI in the past month (figure 1).

The meaning and context of the research study was explained to students and their parents through classroom and parent meetings under the supervision of a teacher. Informed consent was obtained by both students and their parents. Standardised training was provided to study personnel (ie, clinical psychology or psychiatry postgraduate students, psychiatrists) who collected the in-class data, under the supervision of a teacher who was blinded to the students' answers.

The MINI-KID was used to interview students who reported NSSI in the past month. The clinical diagnostic interview was completed within 4 weeks of completion of the OSI by one of the followings: child and adolescent psychiatrists $(n=7)$, undergraduate students who major in psychiatry or psychology $(n=4)$ and a school counsellor $(n=1)$. All of the interviewers had participated in 4 days of MINI-KID training, and their average reliability was kappa $=0.60$. 


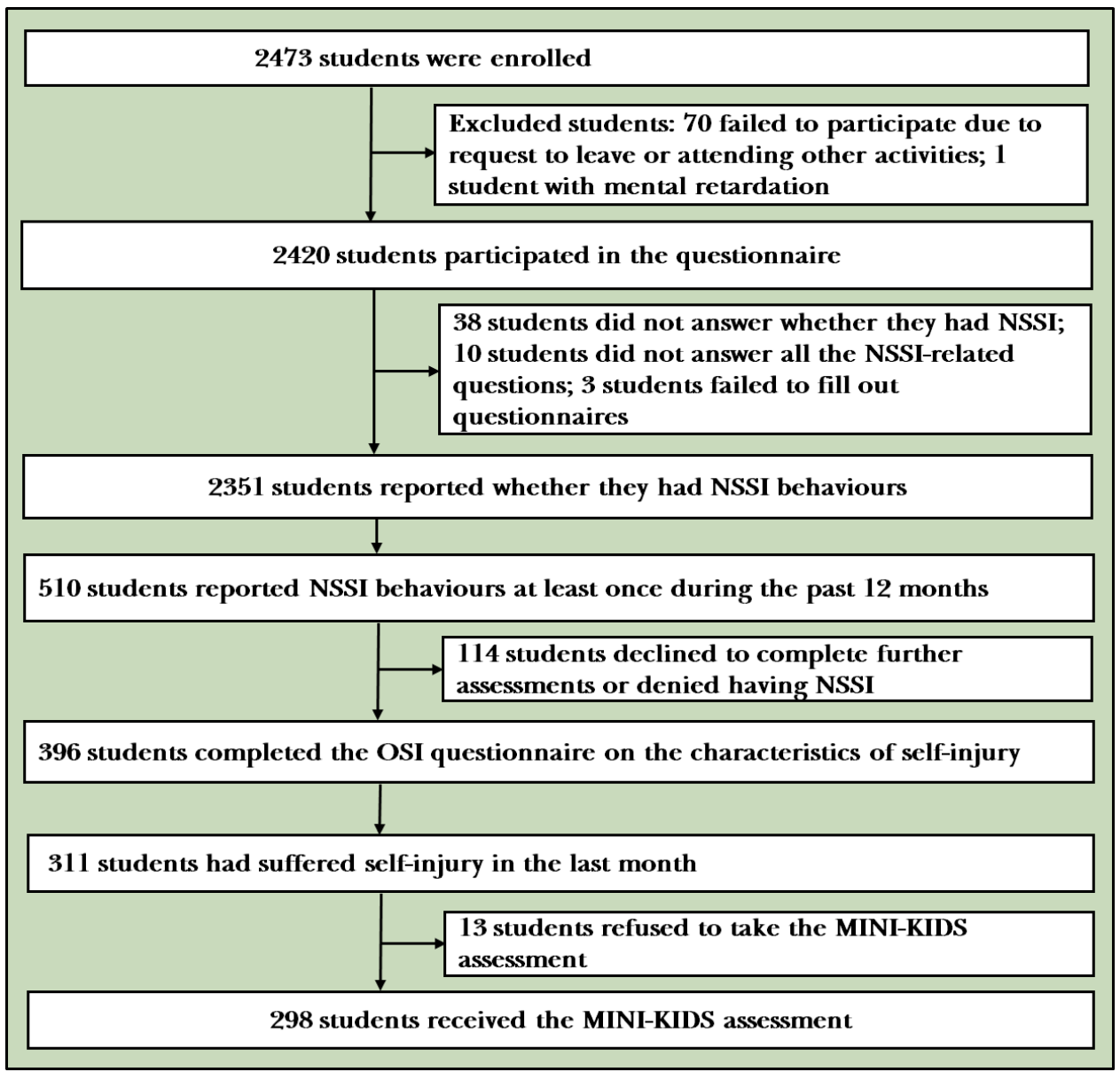

Figure 1 Flowchart of the study. MINI-KID, Mini-International Neuropsychiatric Interview for Children and Adolescents; NSSI, non-suicidal self-injury; OSI, Ottawa Self-Injury Inventory.

\section{Statistical analysis}

Descriptive statistics and Spearman correlation analyses were used to analyse the data. Sex differences were examined by the $\chi^{2}$ or Fisher's exact tests and the MannWhitney $\mathrm{U}$ test for non-normally distributed variables. All tests were two tailed and a $\mathrm{p}$ value $<0.05$ was considered statistically significant.

The presence of NSSI was dichotomised into $0=$ no NSSI and 1=at least one incidence of NSSI in the past 12 months. Self-injury method and body location were also coded as $0=$ no and $1=y e s$. Twenty-two self-injury locations were recoded into seven categories (head and face, neck, chest and back, abdomen, genitals and buttocks, upper arms and legs) and 17 methods of self-injury were recoded into 11 categories (cutting and piercing, scratching, biting, excessive use of street drugs or alcohol, hitting, eating or drinking things that are not food, headbanging, burning, hair pulling, interfering with wound healing and trying to break bones).

\section{RESULTS}

Frequencies and characteristics of NSSI

A total of 2351 students (the return rate of the questionnaire was $97.9 \%$ ) answered whether they had any NSSI behaviour and 396 out of $510(77.6 \%)$ students reported more characteristics in the second phase. NSSI behaviour occurring at least once during the past 12 months was reported in $21.7 \%$ of students $(\mathrm{n}=510 ; 18.5 \%$ male, $24.9 \%$ female $\left.\left(\chi_{1}^{2}=14.034, \mathrm{p}<0.001\right)\right)$. Of these, $13.2 \%(\mathrm{n}=311)$ reported NSSI within the past month (table 1$)$. The mean age of onset was 9.7 years $(S D=2.7$; $\min =3$, $\max =14)$ and the average age of onset was significantly younger for males (9.09 years, $S D=2.85$ ) than females (10.1 years, $S D=2.4 ; t=3.472, d f=362, \mathrm{p}=0.01)$.

Reported methods of engaging in NSSI were as follows: scratching (40.9\%), biting (31.6\%), hitting (24.7\%), interfering with wound healing $(23.0 \%)$, hair pulling (23.0\%), nail-biting/injuries $(22.0 \%)$ and cutting (18.4\%). More than one method of NSSI was reported by $75.4 \%$ of students and $21 \%$ of students reported they used more than four. Spearman correlation analysis showed that the frequency of NSSI within 12 months and the number of self-injury methods were positively correlated $(r=0.143, \mathrm{p}<0.011)$. The Mann-Whitney $\mathrm{U}$ test showed that female students reported more methods of NSSI than male students $(Z=-3.133, \mathrm{p}<0.002)$. A $\chi^{2}$ analysis was also conducted to further examine sex differences in the methods of NSSI. The result revealed that females were more likely than males to engage in biting, cutting, piercing body parts, nail-biting/injuries and interfering 
Table 1 Frequencies of reported NSSI for total sample and by sex

\begin{tabular}{|c|c|c|c|}
\hline & $\begin{array}{l}\text { Total } \\
n=510(\%)\end{array}$ & $\begin{array}{l}\text { Males } \\
n=221(\%)\end{array}$ & $\begin{array}{l}\text { Females } \\
\mathrm{n}=289(\%)\end{array}$ \\
\hline \multicolumn{4}{|c|}{ In the past month } \\
\hline At least once & $256(50.2)$ & $114(51.6)$ & $142(49.1)$ \\
\hline Weekly & $36(7.1)$ & $15(6.8)$ & $21(7.3)$ \\
\hline Daily & $19(3.71)$ & $8(3.6)$ & $11(3.8)$ \\
\hline \multicolumn{4}{|c|}{ In the past 6 months } \\
\hline $1-5$ times & $314(61.6)$ & $146(66.1)$ & $168(58.1)$ \\
\hline Monthly & $29(5.7)$ & $11(5.0)$ & $18(6.2)$ \\
\hline Weekly & $31(6.1)$ & $13(5.9)$ & $18(6.2)$ \\
\hline Daily & $16(3.1)$ & $8(3.6)$ & $8(2.8)$ \\
\hline \multicolumn{4}{|c|}{ In the past 12 months } \\
\hline $1-5$ times & $333(65.3)$ & $138(62.4)$ & $195(67.5)$ \\
\hline Monthly & $80(15.7)$ & $39(17.6)$ & $41(14.2)$ \\
\hline Weekly & 27 (5.3) & $10(4.5)$ & $17(5.9)$ \\
\hline Daily & $15(2.9)$ & $6(2.7)$ & $9(3.1)$ \\
\hline
\end{tabular}

NSSI, non-suicidal self-injury.

with wound healing. Conversely, males were more likely than females to report hitting. No significant sex differences were found for other methods (table 2).

Students reported the most common sites of injury were hands $(73.0 \%)$, followed by scalp $(26.3 \%)$ and lips
(17.2\%). Two-thirds of students who engaged in NSSI $(67.0 \% ; \mathrm{n}=152)$ reported injuring more than 1 body part, $19.4 \%(\mathrm{n}=44)$ reported injuring more than 4 body parts and $1.8 \%(n=4)$ of students reported 10 injury locations. There was a significant positive relationship with the frequency of NSSI and the number of self-injury locations $(r=0.167, \mathrm{p}<0.003) \cdot \chi^{2}$ analyses were conducted to further examine sex differences in the location of NSSI. The result revealed that males were more likely than females to injure their buttocks and females were more likely than males to injure their lips and hands/fingers. There were no sex differences in any other injury location or in the total number of sites injured $(Z=-1.107, p=0.268)$ (table 3 ).

\section{Functions/motivations of NSSI}

The reasons for NSSI most frequently reported by students were for internal emotion regulation (87.9\%), social influence $(57.8 \%)$, external emotion regulation $(82.3 \%)$ and sensation seeking $(28.3 \%)$. Table 4 lists the reported functions of NSSI by sex.

\section{Addictive features and relief following NSSI}

Among those students who reported NSSI in the past 12 months, 400 reported their addictive features, and 387 reported feelings of relief after NSSI. Addictive feature scores were between 0 and $22(\mathrm{M}=2.05 ; S D=1.55)$. Higher addictive feature scores were related to more frequent NSSI $(r=0.421, \mathrm{p}=0.000)$ and with feelings of relief

Table 2 Reported method of NSSI for total sample and by sex

\begin{tabular}{|c|c|c|c|c|c|c|c|}
\hline \multirow[b]{2}{*}{ Method of self-injury (n) } & \multirow[b]{2}{*}{$\mathbf{n}$} & \multicolumn{2}{|l|}{ Males } & \multicolumn{2}{|c|}{ Females } & \multirow[b]{2}{*}{$\chi^{2}$} & \multirow[b]{2}{*}{$P$ value } \\
\hline & & $\mathrm{n}=171$ & $\%$ & $\mathrm{n}=\mathbf{2 2 5}$ & $\%$ & & \\
\hline Scratching & 162 & 65 & 38.0 & 97 & 43.1 & 0.465 & 0.470 \\
\hline Biting & 125 & 40 & 23.4 & 85 & 37.8 & 8.500 & 0.004 \\
\hline Hitting & 98 & 51 & 29.8 & 47 & 20.9 & 4.800 & 0.033 \\
\hline Interfering with wound healing & 91 & 23 & 13.5 & 68 & 30.2 & 14.400 & 0.000 \\
\hline Hair pulling & 91 & 35 & 20.5 & 56 & 24.9 & 0.834 & 0.400 \\
\hline Severe nail-biting and/or nail injuries & 87 & 28 & 16.4 & 59 & 26.2 & 4.990 & 0.027 \\
\hline Cutting & 73 & 21 & 12.3 & 52 & 23.1 & 7.050 & 0.009 \\
\hline Piercing skin with sharp pointy object & 66 & 18 & 10.5 & 48 & 21.3 & 7.650 & 0.006 \\
\hline Trying to break bones & 59 & 27 & 15.8 & 32 & 14.2 & 0.286 & 0.670 \\
\hline Piercing of body parts & 22 & 7 & 4.1 & 15 & 6.7 & 1.109 & 0.380 \\
\hline Excessive use of alcohol & 22 & 12 & 7.0 & 10 & 4.4 & 1.362 & 0.270 \\
\hline Trying to break bones & 14 & 4 & 2.3 & 10 & 4.4 & 1.193 & 0.410 \\
\hline Eating or drinking things that are not food & 7 & 3 & 1.8 & 4 & 1.8 & - & 1.000 \\
\hline Burning & 7 & 4 & 2.3 & 3 & 1.3 & - & 0.470 \\
\hline Taking too little medication & 4 & 1 & 0.6 & 3 & 1.3 & - & 0.640 \\
\hline Taking too much medication & 2 & 1 & 0.6 & 1 & 0.4 & - & 1.000 \\
\hline Excessive use of street drugs & 2 & 1 & 0.6 & 1 & 0.4 & - & 1.000 \\
\hline
\end{tabular}

Symbol (-) indicates that Fisher's exact test was computed.

NSSI, non-suicidal self-injury. 
Table 3 Reported body area injured for total sample and by sex

\begin{tabular}{|c|c|c|c|c|c|c|c|}
\hline \multirow[b]{2}{*}{ Body location } & \multirow[b]{2}{*}{$n=396$} & \multicolumn{2}{|l|}{ Males } & \multicolumn{2}{|c|}{ Females } & \multirow[b]{2}{*}{$\chi^{2}$} & \multirow[b]{2}{*}{$P$ value } \\
\hline & & $\mathrm{n}=171$ & $\%$ & $n=225$ & $\%$ & & \\
\hline Hands/fingers & 289 & 115 & 67.3 & 174 & 77.3 & 5.282 & 0.026 \\
\hline Scalp & 104 & 51 & 29.8 & 53 & 23.6 & 1.980 & 0.167 \\
\hline Lips & 68 & 19 & 11.1 & 49 & 21.8 & 7.807 & 0.007 \\
\hline Lower arm/wrist & 63 & 21 & 12.3 & 42 & 18.7 & 2.975 & 0.960 \\
\hline Thigh/knee & 59 & 27 & 15.8 & 32 & 14.2 & 0.193 & 0.671 \\
\hline Face & 55 & 25 & 14.6 & 30 & 13.3 & 0.134 & 0.770 \\
\hline Upper arm/elbow & 46 & 21 & 12.3 & 25 & 11.1 & 0.129 & 0.753 \\
\hline Inside mouth & 34 & 9 & 5.3 & 25 & 11.1 & 4.243 & 0.046 \\
\hline Lower leg/ankle & 34 & 11 & 6.4 & 23 & 10.2 & 1.783 & 0.208 \\
\hline Neck/throat & 25 & 7 & 4.1 & 18 & 8.0 & 2.512 & 0.144 \\
\hline Foot/toes & 24 & 11 & 6.4 & 13 & 5.8 & 0.730 & 0.833 \\
\hline Shoulder(s) & 24 & 9 & 5.3 & 15 & 6.7 & 0.337 & 0.672 \\
\hline Nose & 23 & 11 & 6.4 & 12 & 5.3 & 0.214 & 0.669 \\
\hline Back & 21 & 5 & 2.9 & 16 & 7.1 & 3.397 & 0.730 \\
\hline Ear(s) & 17 & 6 & 3.5 & 11 & 4.9 & 0.451 & 0.620 \\
\hline Eye(s) & 16 & 6 & 3.5 & 10 & 4.4 & 0.220 & 0.798 \\
\hline Abdomen & 13 & 6 & 3.5 & 7 & 3.1 & 0.048 & 1.000 \\
\hline Hips/buttock & 9 & 8 & 4.7 & 1 & 0.4 & 7.843 & 0.006 \\
\hline Genitals & 3 & 2 & 1.2 & 1 & 0.4 & - & 0.580 \\
\hline Chest & 2 & 1 & 0.6 & 1 & 0.4 & - & 1.000 \\
\hline Breast(s) & 1 & 1 & 0.6 & 0 & 0.0 & - & 0.432 \\
\hline Rectum & 1 & 1 & 0.6 & 0 & 0.0 & - & 0.432 \\
\hline
\end{tabular}

Symbol (-) indicates that Fisher's exact test was computed.

following NSSI $(r=0.372, \mathrm{p}=000)$. Participants who indicated an instance of past suicide reported higher scores on the addictive features scale $\left(\mathrm{M}_{\text {addictive }}=3.80, S D=5.20\right)$ and feeling relief following NSSI $(\mathrm{M}=7.49, S D=5.96)$ than those who did not $\left(\mathrm{M}_{\text {addictive }}=1.53, S D=3.08, t_{(109.245)}=-3.960\right.$, $\left.\mathrm{p}=0.000 ; \mathrm{M}_{\text {relief }}=5.50, S D=5.26, t_{(374)}=0.003\right)$. Compared with students who had NSSI urges but did not take immediate action $\left(\mathrm{M}_{\text {addictive }}=1.20, S D=2.28 ; \mathrm{M}_{\text {relief }}=5.10, S D=4.98\right)$, those who engaged in NSSI immediately following the urge $\left(\mathrm{M}_{\text {addictive }}=3.97, S D=5.49 ; \mathrm{M}_{\text {relief }}=7.97, S D=6.02\right)$ had higher addictive features and feelings of relief ( $t_{\text {addic- }}$ tive $(135.859)=-5.323, \quad \mathrm{p}=0.000 ; \quad t_{\text {relief }} \quad(191.694)=-4.500$, $\mathrm{p}=0.000)$.

\section{NSSI and psychiatric disorders}

A total of 298 students completed the MINI-KID interview. Thirteen students did not receive the interview because they refused, were ill or had other reasons. The findings showed that NSSI coexisted with a number of psychiatric disorders in several students $(43.9 \%)$. Anxiety disorders were the most common $(28.9 \%)$, followed by hypomania or mania $(13.1 \%)$, attention deficit hyperactivity disorder or behavioural disorders $(9.7 \%)$, depression or dysthymia (5.7\%), obsessive-compulsive disorder $(4.4 \%)$ and other disorders $(3.7 \%)$.

\section{DISCUSSION}

\section{Main findings}

The present study assessed the prevalence and characteristics of NSSI in a community sample of Shanghai adolescents, showing it to be a widespread behaviour. Almost a quarter of the adolescents reported that they had intentionally harmed themselves at least once during the past 12 months. This is consistent with results from earlier studies of adolescents in other countries, ${ }^{39}$ but lower than findings from other Chinese cities. ${ }^{824}$

In this study, we found that there were significant sex differences in the prevalence and onset of NSSI, methods used and injury locations. Consistent with previous research, ${ }^{9} 11$ our study also found that girls are more likely than boys to engage in NSSI during the adolescent period. Since girls are more likely than boys to experience negative emotions, ${ }^{25}$ this may explain this finding. As reported by others, our findings show that negative emotions were significantly associated with NSSI among adolescents. $^{26}$

Similar to previous studies, more than half of adolescents with NSSI use more than one method to injure themselves. ${ }^{2}$ Others have also reported that females were more likely to engage in biting, cutting and piercing 
Table 4 Reported functions of NSSI for the total sample and by sex

\begin{tabular}{|c|c|c|c|c|c|}
\hline \multirow[b]{2}{*}{ Functions of self-injury } & \multirow[b]{2}{*}{$\mathbf{n}$} & \multirow{2}{*}{$\begin{array}{l}\text { Males } \\
\mathrm{n}(\%) \\
\end{array}$} & \multirow{2}{*}{$\begin{array}{l}\text { Females } \\
\mathrm{n}(\%)\end{array}$} & \multirow[b]{2}{*}{$\chi^{2}$} & \multirow[b]{2}{*}{$P$ value } \\
\hline & & & & & \\
\hline Internal emotion regulation & 348 & $149(37.9)$ & 199 (50.64) & 0.565 & 0.515 \\
\hline To relieve feelings of sadness or feeling 'down' & 252 & $98(24.9)$ & $154(39.19)$ & 6.106 & 0.015 \\
\hline To punish myself & 225 & $89(22.7)$ & $136(34.61)$ & 3.351 & 0.080 \\
\hline To distract me from unpleasant memories & 199 & $84(21.4)$ & $115(29.26)$ & 0.265 & 0.612 \\
\hline To stop feeling alone and empty & 162 & $65(16.5)$ & $97(24.68)$ & 1.287 & 0.301 \\
\hline $\begin{array}{l}\text { To experience physical pain in one area, when the other } \\
\text { pain I feel is unbearable }\end{array}$ & 146 & $56(14.3)$ & $90(22.9)$ & 2.512 & 0.116 \\
\hline $\begin{array}{l}\text { To produce a sense of being real when I feel numb and } \\
\text { 'unreal' }\end{array}$ & 84 & $31(7.9)$ & $53(13.49)$ & 1.897 & 0.175 \\
\hline To stop me from thinking about ideas of killing myself & 82 & $32(8.1)$ & $50(12.72)$ & 0.849 & 0.383 \\
\hline To stop me from acting out ideas of killing myself & 79 & $33(8.4$ & $46(11.7)$ & 0.122 & 0.800 \\
\hline Social influence & 229 & $101(25.7)$ & $128(32.57)$ & 0.079 & 0.837 \\
\hline To get out of doing something that I don't want to do & 122 & $51(13.0)$ & $71(18.07)$ & 0.210 & 0.662 \\
\hline To avoid getting in trouble for something I did & 100 & $45(11.5)$ & 55 (13.99) & 0.121 & 0.728 \\
\hline To get care and attention from other people & 96 & $43(10.9)$ & $53(13.49)$ & 0.085 & 0.813 \\
\hline To stop my parents from being angry at me & 90 & $40(10.2)$ & $50(12.72)$ & 0.041 & 0.904 \\
\hline To show others how hurt or damaged I am & 86 & $38(9.7)$ & $48(12.21)$ & 0.020 & 0.903 \\
\hline To stop people from expecting so much from me & 84 & $36(9.2)$ & $48(12.21)$ & 0.019 & 0.902 \\
\hline To belong to a group & 42 & $16(4.1)$ & $26(6.62)$ & 0.561 & 0.512 \\
\hline To change my body image and/or appearance & 41 & $21(5.3)$ & $20(5.09)$ & 1.107 & 0.320 \\
\hline External emotion regulation & 326 & $130(33.1)$ & $196(49.87)$ & 10.275 & 0.002 \\
\hline To release unbearable tension & 297 & $118(30.0)$ & $179(45.55)$ & 7.071 & 0.009 \\
\hline To release anger & 260 & $103(26.2)$ & $157(39.95)$ & 4.745 & 0.032 \\
\hline To release frustration & 197 & $73(18.6)$ & $124(31.55)$ & 6.698 & 0.011 \\
\hline Sensation seeking & 112 & $49(12.5)$ & $63(16.03)$ & 0.004 & 1.000 \\
\hline To prove to myself how much I can take & 72 & $31(7.9)$ & $41(10.43)$ & 0.007 & 1.000 \\
\hline To experience a 'high' that feels like a drug high & 59 & $28(7.1)$ & $31(7.89)$ & 0.440 & 0.569 \\
\hline To provide a sense of excitement that feels exhilarating & 51 & $249(6.1)$ & $27(6.87)$ & 0.300 & 0.650 \\
\hline
\end{tabular}

NSSI, non-suicidal self-injury.

methods and males were more likely to use more violent methods like hitting and burning. For example, in a large sample of junior and senior high school students in multiple Chinese cities, Zhang and colleagues ${ }^{24}$ found that females were more likely to engage in scratching, biting and cutting, and males were more likely to engage in pulling hair, headbanging, burning and poisoning. Similarly, Sornberger and colleagues ${ }^{27}$ investigated 1774 adolescents with NSSI and found girls were more likely to report cutting and scratching, and boys were more likely to burn or hit. Our study findings were similar with female students being more likely than males to engage in biting, cutting, piercing body parts, nail-biting/injuries and interfering with wound healing, and male students reported more hitting.

Consistent with our results, a number of studies have found that regulating negative emotions and physiological states ${ }^{12} 14$ and interpersonal influence ${ }^{12} 28$ are the most common reasons reported for NSSI. The evidence for emotion regulation deficits of adolescents with NSSI also comes from functional MRI research where those who engaged in NSSI showed significantly more arousal in the limbic structures like the amygdala, hippocampus and anterior cingulate cortex than those with no NSSI. This provides support for the idea that adolescents with NSSI have greater impulsivity and lower distress control, and the connection between emotions and bad memories is enhanced. ${ }^{29}$

Social influence is another common function of NSSI in adolescents. It may be that adolescents with NSSI behaviour are not able to connect with others through regular communication and social skills. Claes and colleagues ${ }^{28}$ found adolescents with NSSI reported more skill deficits compared with their peers. Similarly, Nock and Prinstein ${ }^{12}$ also found that those who engage in NSSI lacked the ability to solve social problems. The lack of 
interpersonal skills can lead to difficulties in maintaining meaningful social relationships, thus reducing the level of social support. Many studies have supported the view that adolescents with NSSI behaviour significantly reduced their social support. For example, investigators conducted in-depth interviews with 40 individuals who self-injure and found that those who engage in NSSI feel more aloneness. ${ }^{30}$

Unlike the study of You et $a l,{ }^{11}$ our study shows that emotional regulation is still the primary reason for NSSI in adolescents rather than belonging to a group. There may be two reasons for this difference. One is that peer pressure is related to age, with adolescent peer pressure showing an inverted U-shaped age pattern ${ }^{31}$ and will significantly increase from grade 6 to $8 .^{32}$ The sample from You et al's study is 8th grade, while our sample is from 6th to 8th grades, so the peer pressure is different between the two samples. Second, it may be due to the influence of social media on the values of Chinese teenagers, which is different from 5 to 6 years ago. Today's teenagers are more individualised and independent. ${ }^{33}$

\section{Limitations}

A limitation of the study is that we used self-report to evaluate NSSI which may be subject to recall bias. Future studies may wish to use ecological momentary assessment to mitigate this bias. ${ }^{26}$ Additionally, the study measures used were translations from the English versions and further validity studies using these translated measures should be undertaken.

\section{Implications}

The study is one of the first to evaluate the characteristics of NSSI among middle school students in China. In addition to contributing to the knowledge on NSSI in adolescents, it provides important information for teachers, clinicians and researchers highlighting the association between NSSI and emotional regulation and social interaction. The findings can provide direction for the prevention and intervention of NSSI. Specifically, attention should be given to students or patients who have difficulty in emotional regulation or lack of social skills, such as those with social anxiety, autism or intellectual developmental disorder. Given the prevalence of the behaviour, school mental health professionals must be aware of how to manage NSSI within the school setting.

Authors' contributions FZ completed the data collection and analysis, classification and draw of the full text. PFC polished the full text. HY was responsible for organising surveys. WL assisted in data analysis. WC guided each part of the research and the publication of this paper. ZX gave some suggestions on research design and article writing.

Funding This study has been funded by the Shanghai Women and Children's Committee (2014SHET04), the Shanghai Education Commission Research Program (HJTY2012-A06) and the Shanghai High-End Pediatrics Overseas Research Team Construction Project (GDEK201702).

Competing interests None declared.

Patient consent for publication Not required.
Ethics approval The study was approved by the Institutional Review Board of Shanghai Mental Health Center (2014-24).

Provenance and peer review Not commissioned; externally peer reviewed.

Data availability statement All data relevant to the study are included in the article or uploaded as supplementary information.

Open access This is an open access article distributed in accordance with the Creative Commons Attribution Non Commercial (CC BY-NC 4.0) license, which permits others to distribute, remix, adapt, build upon this work non-commercially, and license their derivative works on different terms, provided the original work is properly cited, appropriate credit is given, any changes made indicated, and the use is non-commercial. See: http://creativecommons.org/licenses/by-nc/4.0/.

\section{REFERENCES}

1 Martin G, Swannell SV, Hazell PL, et al. Self-Injury in Australia: a community survey. Med J Aust 2010;193:506-10.

2 Glenn CR, Klonsky ED. A multimethod analysis of impulsivity in nonsuicidal self-injury. Personal Disord 2010;1:67-75.

3 Hanania JW, Heath NL, Emery AA, et al. Non-Suicidal selfinjury among adolescents in Amman, Jordan. Arch Suicide Res 2015;19:260-74.

4 Ammerman BA, Jacobucci R, Kleiman EM, et al. The relationship between Nonsuicidal self-injury age of onset and severity of selfharm. Suicide Life Threat Behav 2018;48:31-7.

5 Swannell SV, Martin GE, Page A, et al. Prevalence of nonsuicidal selfinjury in nonclinical samples: systematic review, meta-analysis and meta-regression. Suicide Life Threat Behav 2014;44:273-303.

6 Wan Y, Chen J, Sun Y, et al. Impact of childhood abuse on the risk of Non-Suicidal self-injury in mainland Chinese adolescents. PLoS One 2015;10:e0131239

7 Wan Y-H, Xu S-J, Chen J, et al. Longitudinal effects of psychological symptoms on non-suicidal self-injury: a difference between adolescents and young adults in China. Soc Psychiatry Psychiatr Epidemiol 2015;50:237-47.

8 Tang J, Yang W, Ahmed NI, et al. Stressful life events as a predictor for Nonsuicidal self-injury in southern Chinese adolescence: a crosssectional study. Medicine 2016;95:e2637.

9 Gratz KL, Latzman RD, Young J, et al. Deliberate self-harm among underserved adolescents: the moderating roles of gender, race, and school-level and association with borderline personality features. Personal Disord 2012;3:39-54.

10 Zetterqvist M, Lundh L-G, Dahlström O, et al. Prevalence and function of non-suicidal self-injury (NSSI) in a community sample of adolescents, using suggested DSM-5 criteria for a potential NSSI disorder. J Abnorm Child Psychol 2013;41:759-73.

11 You J, Lin M-P, Leung F. Functions of nonsuicidal self-injury among Chinese community adolescents. J Adolesc 2013;36:737-45.

12 Nock MK, Prinstein MJ. A functional approach to the assessment of self-mutilative behavior. J Consult Clin Psychol 2004;72:885-90.

13 Laye-Gindhu A, Schonert-Reichl KA. Nonsuicidal Self-Harm Among Community Adolescents: Understanding the "Whats" and "Whys" of Self-Harm. J Youth Adolesc 2005;34:447-57.

14 Klonsky ED. The functions of deliberate self-injury: a review of the evidence. Clin Psychol Rev 2007;27:226-39.

15 Markus HR, Kitayama S. Culture and the self: implications for cognition, emotion, and motivation. Psychol Rev 1991;98:224-53.

16 Cheng WH. The assessment study on the mental health needs of children and adolescents aged 4-18 years old in Shanghai; 2013, Report of Shanghai Education Commission.

17 Martin J, Cloutier PF, Levesque C, et al. Psychometric properties of the functions and addictive features scales of the Ottawa self-injury inventory: a preliminary investigation using a university sample. Psychol Assess 2013;25:1013-8.

18 Nixon MK, Levesque C, Preyde M, et al. The Ottawa self-injury inventory: evaluation of an assessment measure of nonsuicidal selfinjury in an inpatient sample of adolescents. Child Adolesc Psychiatry Ment Health 2015;9:26.

19 Csorba J, Dinya E, Plener P, et al. Clinical diagnoses, characteristics of risk behaviour, differences between suicidal and non-suicidal subgroups of Hungarian adolescent outpatients practising self-injury. Eur Child Adolesc Psychiatry 2009;18:309-20.

20 Plener PL, Fischer CJ, In-Albon T, et al. Adolescent non-suicidal selfinjury (NSSI) in German-speaking countries: comparing prevalence rates from three community samples. Soc Psychiatry Psychiatr Epidemiol 2013;48:1439-45.

21 Fang Z, Wen-hong C, Ze-ping X, et al. Study on reliability and validity of Chinese version of Ottaw a self-injury inventory. J Shanghai Jiaotong Univ 2015;35:460-4. 
22 Sheehan DV, Sheehan KH, Shytle RD, et al. Reliability and validity of the mini international neuropsychiatric interview for children and adolescents (MINI-KID). J Clin Psychiatry 2010;71:313-26.

23 Yuxin Liu J, Wang Y. The reliability and validity of mini internationa neuropsychiatric interview for children and adolescents. Chinese Mental Health Journal 2011;25:8-13.

24 Zhang S-C, Tao F-B, Wu X-Y, et al. Low health literacy and psychological symptoms potentially increase the risks of non-suicidal self-injury in Chinese middle school students. BMC Psychiatry 2016;16:327.

25 Breslau J, Gilman SE, Stein BD, et al. Sex differences in recent firstonset depression in an epidemiological sample of adolescents. Trans/ Psychiatry 2017;7:e1139.

26 Kranzler A, Fehling KB, Lindqvist J, et al. An ecological investigation of the emotional context surrounding Nonsuicidal Self-Injurious thoughts and behaviors in adolescents and young adults. Suicide Life Threat Behav 2018;48:149-59.

27 Sornberger MJ, Heath NL, Toste JR, et al. Nonsuicidal self-injury and gender: patterns of prevalence, methods, and locations among adolescents. Suicide Life Threat Behav 2012;42:266-78.
28 Claes L, Muehlenkamp J, Vandereycken W, et al. Comparison of non-suicidal self-injurious behavior and suicide attempts in patients admitted to a psychiatric crisis unit. Pers Individ Dif 2010;48:83-7.

29 Plener PL, Bubalo N, Fladung AK, et al. Prone to excitement: adolescent females with Non-suicidal self-injury (NSSI) show altered cortical pattern to emotional and NSS-related material. Psychiatry Res 2012;203:146-52.

30 Adler PA, Adler P. Self-Injurers as Loners: the social organization of solitary deviance. Deviant Behav 2005;26:345-78.

31 Brown BB, Clasen DR, Eicher SA. Perceptions of peer pressure, peer conformity dispositions, and self-reported behavior among adolescents. Dev Psychol 1986;22:521-30.

32 Helfert S, Warschburger P. The face of appearance-related social pressure: gender, age and body mass variations in peer and parental pressure during adolescence. Child Adolesc Psychiatry Ment Health 2013;7:16.

33 Wang M. The study on the problems of adolescents values in the We-Media era, zhengzhou university; 2016.

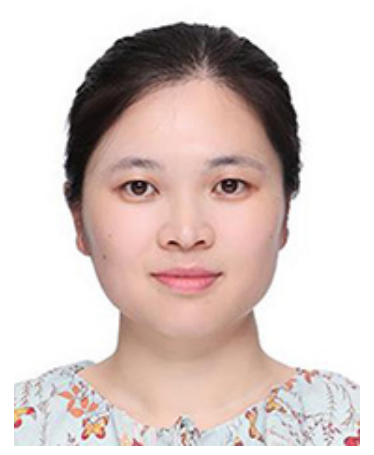

Fang Zhang obtained a master degree from Shanghai Jiaotong University on Clinic applied psychology major in 2015. Since 2015, She has been working as psychotherapist in the department of Medical Psychology of Shanghai General Hospital. Her clinical work mainly provides psychotherapy for adolescents and their families. Her research interests include the emotional and behavioral problems, especially children and adolescents. 